\title{
HUMAN DECIDUAL CELLS ACTIVITY IN WOMEN WITH SPONTANEOUS ABORTIONS OF PROBABLE CMV AETIOLOGY DURING THE FIRST TRIMESTER OF GESTATION. AN IMMUNOHISTOCHEMICAL STUDY WITH CMV-ASSOCIATED ANTIGEN
}

\author{
Demetrio Tamiolakis ${ }^{1}$, Ioannis Venizelos ${ }^{2}$, Maria Lambropoulou ${ }^{3}$, Athanasia Kotini ${ }^{4}$, Sophia Barbagadaki', \\ Sylva Nikolaidou', Panagiotis Boglou ${ }^{3}$, Nikolas Papadopoulos ${ }^{3}$
}

General Hospital of Chania, Greece: Department of Cytology ${ }^{1}$; Ippokration Hospital of Salonica, Greece: Department of Pathology2; Democritus University of Thrace, Greece: Department of Histology - Embryology ${ }^{3}$; Department of Medical Physics $^{4}$

Summary: Aim: To determine the expression of CMV-associated antigen in the human decidual endometrial stromal cells in spontaneous abortions with no evidence of maternal relapse during the first trimester of gestation. Experimental design: We examined 15 placentas resulting from intrauterine fetal death after spontaneous abortion during the $8^{\text {th }}, 10^{\text {th }}$, and $12^{\text {th }}$ week of gestation respectively, and in which CMV reactivation was ruled out from serological evaluation of the pregnant women at admission, versus equal controls after voluntary abortion following well-documented maternal viral recurrence. In addition, a panel of monoclonal antibodies for the identification of leukocytes (CD45/LCA), B-lymphocytes (CD20/L-26), and T-lymphocytes (CD45RO/UCHL1), was performed. All women received hormonal medication to support gestation, in the cases of spontaneous abortions. Results: Immunohistochemical examination using a specific antibody against cytomegalovirus showed large multinucleated infected cells with intranuclear inclusions, located primarily in the decidual stroma within a lymphoplasmacytic infiltrate in the cases of spontaneous abortions. No evidence of infection was observed in the chorionic villi. In the cases of voluntary abortions same findings were observed in the relevant areas, and a strong evidence of infection was observed in the chorionic villi. Conclusion: This study demonstrates 1) that the decidual endometrial stromal cells can express the CMV-associated antigen prior to serological manifestation of the viral replication, 2) the expression of the antigen is higher in cases of hormonal administration to support gestation. In these cases a mild mononuclear infiltrate of UCHL1 (T marker) positive cells, accompanies the CMV-associated antigen positive cells.

Key words: CMV-associated antigen; Human decidual cells; Estradiol; Immunohistochemistry

\section{Introduction}

Human cytomegalovirus (CMV) infection, which usually has a benign course in immunocompetent individuals, can have catastrophic consequences during pregnancy (6). Primary CMV infection during gestation poses a 30 to $40 \%$ risk of intrauterine transmission and clinical disease $(36,37)$. Reactivated infection is associated with at least a 10 -fold-lower rate of transmission. Congenital CMV infection is a relatively common occurrence, as approximately 1 to $4 \%$ of newborns in the United States and Europe are infected with CMV (6), and transmission could be higher in developing countries (9). Many infected infants show no clinical manifestations of the congenital CMV syndrome. Symptomatic infants often succumb in the neonatal period (12\%), and most survivors have permanent debilitating se- quelae, including mental retardation, vision loss, and sensorineural deafness. Since CMV establishes latent infections in granulocyte-dendritic progenitors $(17,24,35)$, the fetus may also become infected after reactivation of maternal infection, a scenario that is usually associated with less severe clinical disease in the offspring $(14,36)$. CMV seroconversion rates and restriction endonuclease analyses of virus strains indicate that heterosexual activity $(7,8,13,19)$ and contact with young children $(21,29)$ are the major modes of virus dissemination in women of childbearing age.

Despite the morbidity and mortality associated with prenatal CMV infection, little is known about how the virus infects the conceptus. Approximately 15\% of women with primary infections during early pregnancy abort spontaneously (16). In this case the placenta, but not the fetus, shows evidence of infection, which suggests that placental 
involvement is important in its own right and precedes virus transmission to the fetus $(4,20,26)$. Later in pregnancy CMV infection causes premature delivery and, in $25 \%$ of affected infants, intrauterine growth retardation (22), outcomes that are often associated with placental pathology. Numerous reports indicate that placentas from these births also contain viral proteins $(26,27)$, suggesting that placental infection and virus transmission to the infant are related causally.

To the best of our knowledge no previous report exists on Medline database up to now, concerning CMV antigen expression by human endometrial decidual cells.

In our series we focused on CMV signs of infection in cases of spontaneous abortions with no maternal re-involvement, compared to controls with well-established CMV affection of the pregnant women. We concluded that decidual stromal endometrial cells express the CMV-associated antigen prior to the serological manifestation of the virus. Our results are in harmony with what we know about the virus, that is, placental involvement precedes fetal involvement (12). We also confirmed that the increase in CMV infection observed in pregnancy is caused by reactivation of the virus induced by hormones (23).

\section{Materials and methods}

Samples representing 15 placentas from fetuses after spontaneous (involuntary) abortion occurring in pregnant women once infected by CMV but with no serological evidence of recurrence at admission, administrated with estradiol (300-600 mg per os until the $12^{\text {th }}$ gestational week), and 15 placentas from fetuses after voluntary abortion with well-documented CMV maternal affection, were obtained at $8^{\text {th }}, 10^{\text {th }}$ and $12^{\text {th }}$ week of gestation. Placentas were cut as thick as $3 \mathrm{~mm}$, then fixed in $10 \%$ neutral buffered formaldehyde at $4^{\circ} \mathrm{C}$ for 24 hours and processed for routine paraffin embedding. Paraffin blocks were available in all cases, and three- $\mu \mathrm{m}$ thick tissue sections were stained routinely with hematoxylin - eosin, PAS and Giemsa, and subsequently, using immunohistochemistry. Microscopically, a diagnosis of CMV infection was made on the presence of cytomegalic inclusion bodies. Immunoperoxidase method was performed as follows: sections were deparaffinized in $70 \%$ alcohol and endogenous peroxidase was blocked with $3 \% \mathrm{H}_{2} \mathrm{O}_{2}$ in methanol. Sections were preincubated in $20 \%$ serum of the species from which the secondary antibody was raised and the primary antibody was applied. After overnight incubation at room temperature, the secondary biotinylated antibody was applied for 30 minutes. Staining was visualized using the Vector Elite System (Vector Laboratories, Burlingame, CA) with diaminobenzidine as the chromogen. Sections were counterstained in dilute hematoxylin. The primary antibodies used were as follows: cytomegalovirus (CMV), mouse monoclonal antibody (Dako), (CD45/LCA) leukocyte common antigen, mouse monoclonal antibody (Dako), (CD20/L-26) B-lymphocytes, mouse monoclonal antibody (Dako), and (CD45RO/UCHL1) T-lymphocytes, mouse monoclonal antibody (Dako).

Analysis of CMV positive decidual cells: For each sample, the CMV positive decidual population was assessed by enumeration of labeled cells in each tissue compartment for a minimum of five random fields per section viewed at 40 -fold magnification through a grid. Cell number was calculated per $1 \mathrm{~mm}^{2}$ of tissue section. The counted areas were selected from random placental tissue sections, taking into account that the ratio of the area of the decidual stroma according to the area of the chorionic villi was representative of the entire field. Areas with obvious necrosis or hemorrhages were excluded. Statistical analysis was undertaken using the ANOVA test.

\section{Results}

Five microscopic fields of the placentas were evaluated in each case without knowledge of the clinical data. The sections were examined independently by two observers, and positive cellular staining for each antibody was manifested as fine red cytoplasmic granularity and/or surface membrane expression.

$8^{\text {th }}$ week of gestation: The immunohistochemical study of the placentas, during this period for the detection of CMV positive cells, in cases of spontaneous abortions, showed small clusters or scattered, large-sized CMV positive decidual cells in all settings examined (Fig 1, 2), with percentages varying from 3.2 to 3.9 (mean values, $3.61 \pm 0.16$ ). In the neighboring decidual stroma a slight cell infiltration was observed, consisting of rounded mononuclear cells of approximately $10 \mu \mathrm{m}$ in diameter with an eccentric kidney-shaped nucleus and expressing a CD45/LCA and CD45RO/UCHL1 phenotype. In one of our cases a dense polymorphonuclear infiltrate was observed, surrounding large-sized cells with an intense nuclear membrane positivity to the CMV antigen (fig 3). The microscopic examination (H-E, and PAS) of these cells showed an abundant pale cytoplasm, a nucleus with marginated chromatin, and a prominent inclusion-like eosinophilic nucleolus. The immunohistochemical study of the placentas, in the cases of voluntary abortions, showed a smaller number of large-sized CMV positive decidual cells in all settings examined, with percentages varying from 3.1 to 3.7 (mean values, 3.42 \pm 0.17 ). No inflammatory infiltrates or necrosis were noted in the neighboring decidual stroma.

$10^{\text {th }}$ week of gestation: During this period, in cases of spontaneous abortions, the immunohistochemical examination for the identification of CMV decidual cells, showed a higher number of positive cells, in comparison with those found at $8^{\text {th }}$ week of gestation, with percentages varying from 4.9 to 5.6 (mean values, $5.27 \pm 0.19$ ). The number of inflammatory infiltrates in the decidual stroma, expressing the phenotype CD45/LCA and CD45RO/UCHL1 was minimal. The immunohistochemical study of the placentas, in the cases of voluntary abortions, showed a relatively equal 


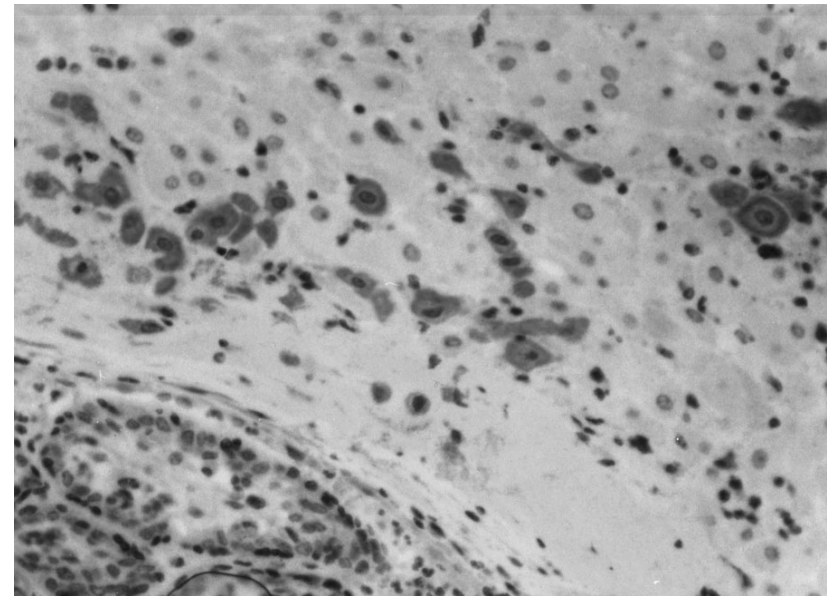

Fig. 1: Aggregates of large-sized CMV positive decidual cells. Immunostaining with CMV antibody, APAAP technique, magnification x 200 .

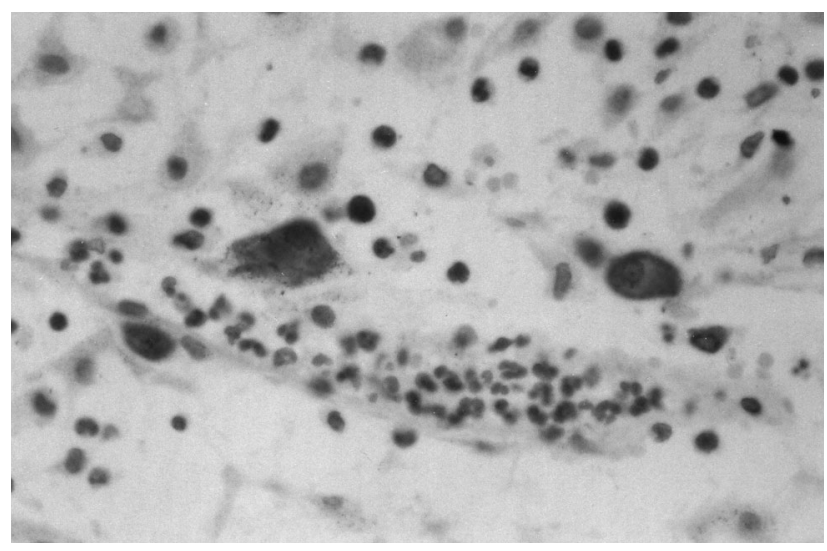

Fig. 3: CMV positive decidual cells against a background of polymorphonuclear infiltrate. Immunostaining with CMV antibody, APAAP technique, magnification $x 400$.

number of large-sized CMV positive decidual cells, in comparison with those found at $8^{\text {th }}$ week of gestation, with percentages varying from 3.2 to 3.9 (mean values, $3.43 \pm 0.18$ ). No inflammatory infiltrates or necrosis were noted in the neighboring decidual stroma.

$12^{\text {th }}$ week of gestation: During this time, an even higher number of CMV positive decidual cells was found, compared to that at $10^{\text {th }}$ week, with percentages varying from 4.8 to 5.7 (mean values, $5.34 \pm 0.23$ ). Respectively, the number of CMV positive decidual cells in the cases of voluntary abortions, was more or less the same as that at $8^{\text {th }}$ and $10^{\text {th }}$ weeks, with percentages varying from 3.2 to 3.7 (mean values, $3.41 \pm 0.17$ ). No differences in the immune reactions were noted in the neighboring decidual stroma in cases of spontaneous abortions as well as in cases of voluntary ones, in comparison to $8^{\text {th }}$ and $10^{\text {th }}$ gestational weeks.

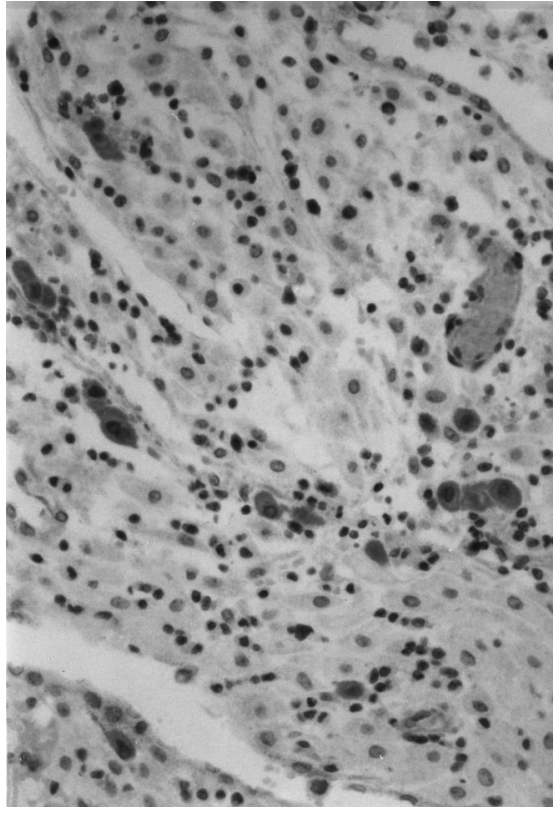

Fig. 2: Isolated large-sized CMV positive decidual cells. Immunostaining with CMV antibody, APAAP technique, magnification $\mathrm{x} 200$.

A statistically significant difference was found between CMV positive cells at $8^{\text {th }}, 10^{\text {th }}$, and $12^{\text {th }}$ gestational week after spontaneous abortions $(\mathrm{p}<0.0001)$. No significant difference was observed between CMV positive cells at $8^{\text {th }}$, $10^{\text {th }}$, and $12^{\text {th }}$ gestational week after voluntary abortions $(\mathrm{p}=0.95)$.

\section{Discussion}

Approximately $15 \%$ of all clinically recognized human pregnancies end in early spontaneous abortion (SAB) (11). Infectious disease is a significant problem in maternal health. An estimated 5\% of maternal deaths reported to the Centers for Disease Control and Prevention are associated with recurrent spontaneous abortion (5). Of these deaths, approximately one half are caused by infection (32). Bacterial, viral, parasitic, fungal, and zoonotic infections have all been associated with recurrent abortion. The association of infection with recurrent abortion is among the most controversial and poorly explored of potential etiologies for reproductive loss.

Embryo is a semi-allograft of a different nature, considering that it contains proteins coming from the father, and unfamiliar to the mother. There is a common sense, that circulating blocking factors protect embryos from maternal lymphocytes which may cause miscarriage due to reaction against paternal antigens. Such factors can be progesterone and chorionic gonadotropin; their levels in blood serum are low, in cases of habitual abortions $(11,18)$. Mixed lymphocyte culture has been applied to detect circulating blocking 
factors. However, the above hypothesis was not confirmed by well-developed perspective studies. In not miscarrying women no circulating blocking factors were detected in serum, to slow down mixed lymphocyte culture. Recently, it was implied, that mixed lymphocyte culture results are representative of habitual abortion consequences rather than the causes of their appearance.

Clinical observations indicate that subclinical infection with CMV and genital CMV excretions are most common during pregnancy $(10,25,38,41)$. The increase in productive CMV infection observed during pregnancy can be caused by increased initial acquisition or by progressive reactivation of latent virus due to an altered immune state or increase in one or more pregnancy hormones.

The latency of human CMV has yet to be demonstrated experimentally. Except for one initial report of studies based on a small series of patients (10), it has not been possible to activate CMV from the leukocytes of large numbers of blood donors who were seropositive for antibodies to CMV (2). The state of the viral genome and the cells in which the virus is present during latency is unknown. Some studies suggest that there may be a low level of replication that is not detected by standard techniques $(1,34)$. Other data favor a nonreplicating state $(31,39,40)$.

The mechanism by which estradiol cares modulate the state of CMV in endometrial cells is unknown. Zerbini et al. (42) have demonstrated that in human embryo tissue culture acidic medium inhibits the production of CMV viral progeny, allowing only the expression of the immediate early and early antigens of the virus (3). It is possible that hormones enable the expression of the late viral genome functions, i.e., late proteins which are inhibited by the low $\mathrm{pH}$. There are other systems in which steroid hormones play a role in modulation of viral replication. Murine mammary tumor virus expression is regulated in vitro by glucocorticoids (33), probably through an interaction of the glucocorticoid receptor complex with a sequence within the long-terminal repeat $(15,30)$. In the case of HSV-2, the addition of hydrocortisone to Raji cells persistently infected with the virus caused a marked increase in virus production (28).

Our results 1) indicate that CMV antigen investigation in human decidual cells can be applied as a routine process for the determination of viral recurrence, and 2) confirm that CMV expression in decidual endometrial stromal cells is induced by estradiol control. Studies of CMV expression in decidual cells would provide new insight into its biological functions.

\section{References}

1. Baringer JR, and Swoveland P. Persistent herpes simplex virus infection in rabbit trigeminal ganglia. Lab Invest 1974;30:230-40.

2. Bayer WL, and Tegtmeier GE. The blood donor: detection and magnitude of CMV carrier state and the prevalence of CMV antibody. Yale J Biol Med 1976:49:5-12.

3. Baker DA, and Plotkin SA. Enhancement of vaginal infection in mice by herpes simplex virus type II with progesterone. Proc Soc Exp Biol Med 1978;158:131-4.
4. Benirschke K, Mendoza GR, Bazeley PL. Placental and fetal manifestations of cytomegalovirus infection. Virchows Arch B Cell Pathol 1974;16:121-39.

5. Berman SM, and Mackay HT, Grimes DA et al. Deaths from spontaneous abortion in the United States. JAMA 1985;253:3119-23.

6. Britt WJ. Congenital cytomegalovirus infection. In P. J. Hitchcock, H. T. MacKay, and J. N. Wasserheit (ed.), Sexually transmitted diseases and adverse outcomes of pregnancy. Washington, D.C.: ASM Press, 1999:269-81.

7. Chandler $\mathrm{SH}$, Handsfield $\mathrm{HH}$, and McDougall JK. Isolation of multiple strains of cytomegalovirus from women attending a clinic for sexually transmitted disease. J Infect Dis 1987;155:655-60.

8. Chandler SH, Holmes KK, Wentworth BB et al. The epidemiology of cytomegaloviral infection in women attending a sexually transmitted disease clinic. J Infect Dis 1985;152:597-605.

9. de Jong MD, Galasso GJ, Gazzard B et al. Summary of the II International Symposium on Cytomegalovirus. Antiviral Res 1998;39:141-62.

10. Diosi P, Moldovan E, and Tomescu N. Latent CMV infection in blood donors. $\mathrm{Br}$ Med J 1969;13;4(684):660-2.

11. Edmonds DK, Lindsay KS, Miller JF et al. Early embryonic mortality in women. Fertil Steril 1982;38:447-53.

12. Fisher S, Genbacev O, Maidji E, Pereira L. Human cytomegalovirus infection of placental cytotrophoblasts in vitro and in utero: implications for transmission and pathogenesis. J Virol 2000;74(15):6808-20.

13. Fowler K B, Pass RF. Sexually transmitted diseases in mothers of neonates with congenital cytomegalovirus infection. J Infect Dis 1991;164:259-64.

14. Fowler KB, Stagno S, Pass RF, Britt WJ, Boll TJ, Alford CA. The outcome of congenital cytomegalovirus infection in relation to maternal antibody status. N Engl J Med 1992;326:663-7.

15. Govindan MV, Spiess E, Majors J. Purified glucocorticoid receptor hormone complex from rat liver cytosol binds specifically to cloned mouse mammary tumor virus long terminal repeats in vitro. Proc Natl Acad Sci USA 1982; 79:5157-61.

16. Griffiths PD, Baboonian C. A prospective study of primary cytomegalovirus infection during pregnancy: final report. Br J Obstet Gynaecol 1984;91:307-15.

17. Hahn G, Jores R, Mocarski ES. Cytomegalovirus remains latent in a common precursor of dendritic and myeloid cells. Proc Natl Acad Sci USA 1998;95:3937-42

18. Haller H, Radillo O, Rukavina D et al. An immunohistochemical study of leukocytes in human endometrium, first and third trimester basal decidu. J Reprod Immunol, 1993;23(1):41-9.

19. Handsfield HH, Chandler SH, Caine VA et al. Cytomegalovirus infection in sex partners: evidence for sexual transmission. J Infect Dis 1985;151:344-8.

20. Hayes K, Gibas H. Placental cytomegalovirus infection without fetal involvement following primary infection in pregnancy. J Pediatr 1971;79:401-5.

21. Hutto C, Ricks R, Garvie M, Pass RF. Epidemiology of cytomegalovirus infections in young children: day care vs. home care. Pediatr Infect Dis 1985;4:149-52.

22. Istas AS, Demmler GJ, Dobbins JG, Stewart JA. Surveillance for congenital cytomegalovirus disease: a report from the National Congenital Cytomegalovirus Disease Registry. Clin Infect Dis 1995;20:665-70.

23. Kleinman D, Sarov I, Insler V. Reactivation of cytomegalovirus in endometrial cells by estradiol. Cynecol Obstet Invest 1986;21:136-43.

24. Kondo K, Kaneshima H, Mocarski ES. Human cytomegalovirus latent infection of granulocyte-macrophage progenitors. Proc Natl Acad Sci USA 1994;91: 11879-83.

25. Montgomery R, Youngblood L, Medearis DN. Recovery of CMV from the cervix in pregnancy. Pediatrics 1972;49:524-31.

26. Mostoufi-zadeh M, Driscoll SG, Biano SA, Kundsin RB. Placental evidence of cytomegalovirus infection of the fetus and neonate. Arch Pathol Lab Med 1984; 108:403-6.

27. Muhlemann K, Miller RK, Metlay L, Menegus MA. Cytomegalovirus infection of the human placenta: an immunocytochemical study. Hum Pathol 1992;23: 1234-7.

28. Nishiyama Y, Rapp F. Regulation of persistent infection with herpes simplex virus in vitro by hydrocortisone. J Virol 1979;31:841-4

29. Pass RF, Little EA, Stagno S, Britt WJ, Alford CA. Young children as a probable source of maternal and congenital cytomegalovirus infection. N Engl J Med 1987;316:1366-70

30. Payvar F, Wrange O, Carlstedt Duke J et al. Purified glucocorticoid receptors bind selectively in vitro to a cloned DNA fragment whose transcription is regulated by glucocorticoids in vivo. Proc Natl Acad Sci USA 1981;78:6628-32.

31. Puga A, Rosenthal JP, Openshaw H, Notkins AL. Herpes simplex virus DNA and mRNA sequences in acutely and chronically infected trigeminal ganglia of mice. Virology 1978;89:102-11.

32. Riley LA, Tuomala RE. Infectious diseases and recurrent pregnancy loss. Infect Reprod Med Clin North Am 1991;2:165-74.

33. Ringold GM. lucocorticoid regulation of mouse mammary tumor virus gene expression. Biochim Biophys Acta 1979;560:487-508

34. Schwartz J, Whetsell WO, Elizan TS. Latent herpes simplex virus infection of mice: infectious virus in homogenates of latently infected dorsal root ganglia. J Neuropathol Exp Neurol 1978;37:445-55. 
35. Soderberg-Naucler C, K. Fish KN, Nelson JA. Reactivation of latent human cytomegalovirus by allogeneic stimulation of blood cells from healthy donors. Cell 1997:91:119-26.

36. Stagno S, Pass RF, Cloud G et al. Primary cytomegalovirus infection in pregnancy. Incidence, transmission to fetus, and clinical outcome. JAMA 1986;256 1904-8

37. Stagno S, Pass RF, Dworsky ME et al. Congenital cytomegalovirus infection: the relative importance of primary and recurrent maternal infection. $\mathrm{N}$ Engl J Med 1982;306:945-9.

38. Stern H, Tucker SM. Prospective study of CMV infection in pregnancy. Br Med J 1973;ii:268-70.

39. Stevens JG, Cook ME. Latent herpes simplex virus in spinal ganglia of mice. Science 1971;173:843-5.

40. Walz MA, Price RW, Notkins AL. Latent ganglionic infection with herpes simplex virus types 1 and 2: viral reactivation in vivo after neurectomy. Science 1974; 184:1185-7.

41. Whitley RJ, Alford CA. Chronic intrauterine and perinatal infections. In Galasso, Merigan, Buchanan. Antiviral agents and viral diseases of man. New York: Raven Press, 1979:541-604

42. Zerbini M, Musiani M, Carpi C, Falcieri E. Productive and abortive replication of human cytomegalovirus at different environmental $\mathrm{pH}$ values. Arch Virol $1982 ; 72: 127-31$

Submitted February 2004.

Accepted March 2004.

Assoc. Prof. Nikolaos Papadopoulos,

Democritus University of Thrace,

Dragana, 68100 Alexandroupolis,

Greece.

e-mail: npapad@med.duth.gr 